\title{
Estudio Electroquímico de Monocapas Autoensambladas de Cisteamina Funcionalizadas con 6-metil-2-piridincarboxaldehído
}

\author{
IBETH RENDÓN ENRÍQUEZ a* , JULIO CÉSAR AGUILAR CORDEROb \\ a Facultad de Ciencias Químicas, Universidad Central del Ecuador, Ciudadela Universitaria, Av. América, Quito, Ecuador. \\ b Departamento de Química Analítica, Facultad de Química, UNAM, Circuito Escolar s/n, \\ Ciudad Universitaria, México, D.F. \\ * Correspondencia: lunariel_ibe@hotmail.com \\ Recibido: 2 enero 2011 / Aceptado: 10 julio 2011
}

\section{Resumen}

En este trabajo se presenta un estudio sistemático de la formación de una Monocapa Autoensamblada (MAE) de Cisteamina (CA) sobre electrodos de oro. Esta monocapa fue funcionalizada con 6-metil-2-piridincarboxaldehído (MPC) mediante la formación de una base de Schiff capaz de fijar iones metálicos a fin de cuantificarlos en solución acuosa. Para analizar las propiedades electroquímicas de las superficies de oro modificadas en presencia de un mediador redox se realizaron estudios de Voltamperometría Cíclica (VC) y Espectroscopía Electroquímica de Impedancia (EIS). La respuesta de esta modificación depende de la interacción con el analito (CA, MPC o ión metálico) pero también se tomaron en cuenta las interacciones del medio acuoso de fosfatos (solución amortiguadora) en el que se llevó a cabo los estudios. Mediante dicho estudio se pudo determinar si la monocapa utilizada es apta para ser empleada como un sensor impedimétrico, llegando a establecerse que la base de Schiff no logra estabilizarse en la solución de fosfatos por lo que no es posible utilizar dicho electrodo modificado como un sensor impedimétrico.

Palabras clave: monocapas Autoensambladas (MAEs), Voltamperometría Cíclica (VC), Espectroscopía Electroquímica de Impedancia (EIS), Microscopía Electroquímica de Barrido (SECM).

\section{Electrochemical Study of Self-assembled Monolayer of Cysteamine Functionalized with 6-methyl-2-pirydincarboxaldehyde}

\section{Abstract}

This paper presents a systematic study of the Self-Assembled Monolayer (SAM) of Cisteamine (CA) on gold electrodes functionalized with 6-Methyl-2 Pyridinecarboxaldehyde (MPC) in order to quantitate its binding capacity with metal ions in aqueous solution. The electrochemical properties of gold surfaces modified in the presence of a redox mediator were studied with Cyclic Voltamperommetry (CV) and Electrochemical Impedance Spectroscopy (EIS). The effect of the analyte (CA, MPC or metal ions) and the buffer solution was also evaluated. The Schiff base formed with MPC can not stabilize in the buffer solution, and it is not posible to use the modified electrode as an impedimetric sensor.

Key words: self-Assembled Monolayers (SAMs), Ciclic Voltammetry (CV), Electrochemical Impedance Spectroscopy (EIS), Scanning Electrochemical Microscopy (SECM). 


\section{Introducción}

La formación de MAEs ha ganado interés debido al orden y la facilidad con la que estas se forman sobre la superficie; varios estudios se han llevado a cabo, el más cercano a la experimentación actual detalla la formación de una monocapa de CA funcionalizada con salicilaldehido para el desarrollo de un sensor capaz de cuantificar cobre en concentraciones de hasta $1 \times 10^{-11} \mathrm{M}$ [1]. En la mayor parte de estudios, se elige al oro para la formación de monocapas de tioles, debido a la elevada afinidad entre el azufre del grupo tiol y el oro [2] [3]. Además, el oro es un metal noble, que no reaccionará con el oxígeno ambiental ni con la mayor parte de productos químicos; además, es un metal no tóxico para las células.

\section{Materiales y Métodos}

\subsection{Formación de la monocapa}

Para obtener electrodos modificados, se emplearon electrodos de oro de $1.8 \mathrm{~mm}$ de diámetro (CHInstruments, Austin Texas, USA) sometidos a una limpieza mecánica y electroquímica.

La limpieza mecánica se llevó a cabo mediante un pulido de los electrodos en paños especiales y con alúmina (Buehler) de 0,3 $\mu \mathrm{m}$ y 0,05 $\mu \mathrm{m}$ sucesivamente. Posteriormente los electrodos se lavaron con agua desionizada tipo I (Milli Q Gradient, Millipore). Inmediatamente se realizó una limpieza electroquímica que consiste en un ciclo de voltamperometría cíclica en ácido sulfúrico (J.T. Baker, RA.) 0.5 M desde 0.4V a $1.8 \mathrm{~V}$ a una velocidad de $1 \mathrm{~V} / \mathrm{s}$, hasta que los voltamperogramas sean reproducibles.

A continuación se sumergieron dichos electrodos en una solución de CA $20 \mathrm{mM}$ (Aldrich 99\%) preparada en agua desionizada tipo I en ausencia de luz. Una vez adherida la monocapa se lavó con agua desionizada y se procedió a funcionalizar la CA. La funcionalización consiste en una reacción orgánica de formación de una base de Schiff, para lo cual el sistema se sumergió en una solución 0.1M de MPC (Aldrich 99\%) en etanol absoluto (Mallinckrodt), a $40^{\circ} \mathrm{C}$. En la Figura 1 puede apreciarse la formación de la monocapa de CA y su funcionalización con MPC.

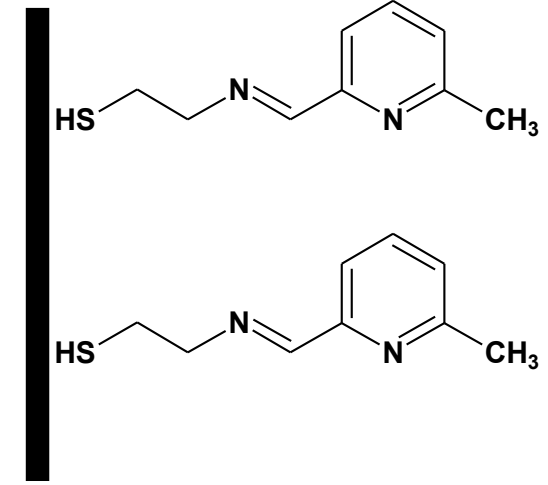

Figura 1. Representación de la formación de la monocapa con CA y su respectiva funcionalización con MPC sobre el electrodo de oro.

Mediante este tratamiento se obtuvo una monocapa con posibilidades de formar complejos con el ion $\mathrm{Cu}^{2+}$.

Es importante que previo a la inmersión en las soluciones del metal a identificar, el electrodo permanezca en un medio húmedo, para lo cual se lo mantuvo en una solución Buffer de fosfatos (PBS) $0.05 \mathrm{M}$ de pH 7 para lo cual se utilizará dihidrógeno fosfato de sodio y monohidrógeno fosfato de sodio (ambos J.T. Baker, R.A.) y además se agregará cloruro de sodio (Aldrich R.A.) a una concentración $50 \mathrm{mM}$ como electrolito soporte.

\subsection{Voltamperometría cíclica}

Para realizar los experimentos de VC es necesario el uso de un mediador. Para la experimentación actual se usó hexocianoferrato (III) de potasio (Aldrich R.A.) $5 \mathrm{mM}$ en solución de PBS.

Para evitar cualquier efecto del oxígeno sobre las determinaciones, se burbujea nitrógeno durante quince minutos en el mediador antes y luego se mantiene una corriente de nitrógeno sobre la solución del mediador mientras se realiza cada medición. Para cada experimento, el electrodo se lavó previamente con agua desionizada tipo l; se armó una celda utilizando tres electrodos, el de referencia $(\mathrm{Ag} / \mathrm{AgCl})$, el contra electrodo que consiste en un electrodo de platino y el electrodo de trabajo, que para este caso es el electrodo de oro modificado, todos inmersos en la solución del mediador. 
El barrido de $\mathrm{VC}$ es de $-0.3 \mathrm{~V}$ a $0.6 \mathrm{~V}$ a una velocidad de barrido de $50 \mathrm{mV} / \mathrm{s}$, valores que deben mantenerse en todos los experimentos. Para los experimentos que implican la formación de la monocapa con CA y la funcionalización con MPC, se procede a colocar los electrodos en cada sustancia durante 5 , $15,30,60,90$ y $120 \mathrm{~min}$, bajo las condiciones antes especificadas; después de cada uno de estos tiempos se hace un barrido de VC.

Utilizando electrodos de oro modificados y funcionalizados se procedió a preparar soluciones de cobre y mercurio de concentraciones en un rango de $1 \times 10^{-12}$ hasta $1 \times 10^{-5} \mathrm{M}$ en solución amortiguadora de p-Benzoquinona (PBQ); los electrodos se sumergieron en cada solución durante 30 minutos, se lavaron con agua desionizada y luego se realizaron barridos de VC.

Para descartar los efectos que presenta la solución amortiguadora en cada una de estas mediciones, se realizaron voltamperogramas dejando los electrodos de oro modificados y funcionalizados en la solución buffer durante tiempos equivalentes a los que pasa el electrodo en las soluciones de cobre, es decir, tiempos de $30,60,90,120,150$ y 180 minutos.

Las soluciones de cobre se prepararon a partir de sulfato de cobre (II) pentahidratado (Aldrich 99.99\%). Para todos los experimentos de VC, se utilizó un potenciostato Solartron 1287.

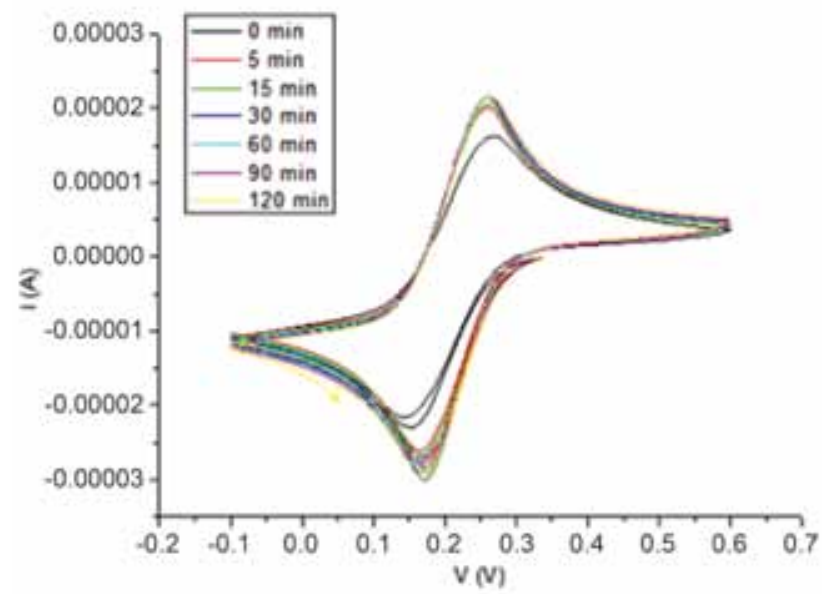

\subsection{Espectroscopía electroquímica de impedancia}

Luego de culminar con cada experimento de VC se procede a realizar un experimento de EIS, para lo cual es necesario determinar el potencial de media onda, potencial al que se llevan a cabo los barridos de EIS. Además, debe fijarse la frecuencia a la que se realizarán todos los experimentos, para lo cual se eligió un rango de $0.1 \mathrm{~Hz}$ hasta $0.1 \mathrm{MHz}$.

Es importante que durante el ensayo se mantenga, al igual que en voltamperometría, una corriente de nitrógeno sobre el mediador, con un burbujeo previo de este gas en el interior del mediador a utilizarse.

En el caso de los experimentos de EIS, se utilizó el potenciostato Solartron 1287 acoplado a un analizador de frecuencias Solartron 1260.

\section{Resultados y Discusión}

\subsection{Formación de la monocapa}

De los experimentos en VC puede apreciarse un ligero aumento en los valores absolutos de corriente de pico de los procesos de oxidación y reducción que presentan el mediador y su reductor conjugado (ilustración 2). Este fenómeno se debe a que el par $\mathrm{Fe}(\mathrm{CN})_{6}^{3-/ 4-}$ exhibe una mejor reversibilidad en el electrodo modificado con CA debido a las fuerzas de atracción electrostáticas entre el grupo amino protonado de la $\mathrm{CA}$ (pKa superficial cercano a 6.7) y $\mathrm{Fe}(\mathrm{CN})_{6}^{3-/ 4-}$.

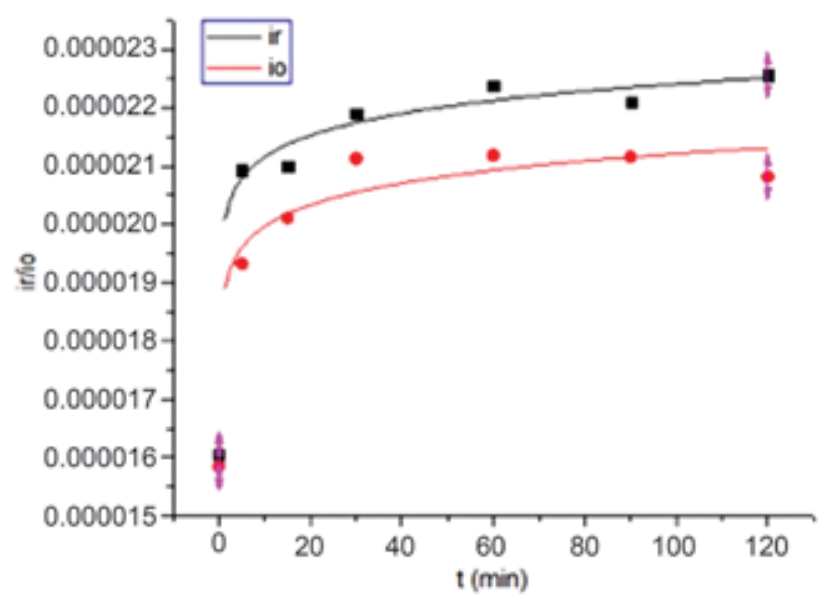

Figura 2. Izquierda: Voltamperogramas cuando el electrodo es mantenido en CA. Derecha: Valores de corrientes de pico de oxidación $\left(i_{0}\right)$ y reducción $\left(i_{r}\right)$ obtenidos de los voltamperogramas del lado izquierdo. 
Ambas corrientes de pico, la anódica y la catódica, se comportan cualitativamente del mismo modo, y tienden a estabilizarse como se muestra en la figura 2 (derecha).

La adsorción de la CA produce cambios en la respuesta de impedancia de los electrodos modificados que se muestran en la figura 3 . Resulta notorio que la resistencia a la transferencia de carga para el par
$\mathrm{Fe}(\mathrm{CN})_{0}^{3-} / \mathrm{Fe}(\mathrm{CN})_{0}^{4-}$ disminuye cuando se ha modificado la superficie del electrodo de oro con CA. Se observó que después de un tiempo más largo de tratamiento con CA esta resistencia aumenta, quizás por un efecto de bloqueo de la superficie aunado a una modificación del valor de $\mathrm{pH}$ en la superficie del electrodo, que probablemente no es posible compensar localmente con la presencia del amortiguador de fosfatos.

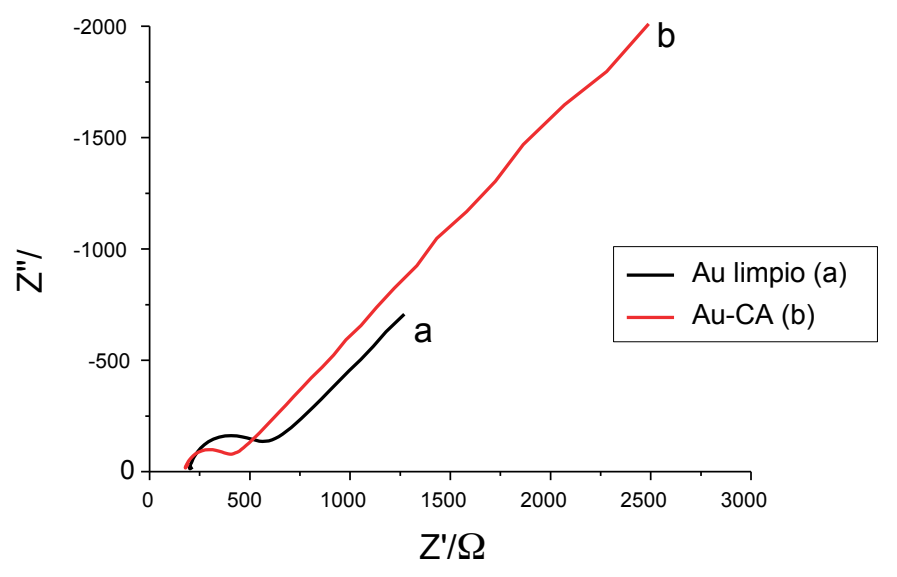

Figura 3. Diagrama de Nyquist para cuando el electrodo de oro está limpio (a) y cuando ha sido sumergido en CA durante 60 minutos (b), el barrido fue realizado en ferricianuro como mediador a un potencial de media onda de $0.21 \mathrm{~V}$.

\subsection{Funcionalización de la CA}

De los experimentos en VC puede apreciarse una disminución en los valores absolutos de corriente de pico en los procesos de oxidación y reducción que presentan el mediador y su reductor conjugado (Figura 4).

Una capa se ha formado sobre la superficie del electrodo; dicha capa tendrá características específicas que impedirán el ingreso del mediador hacia la superficie de oro que pudo haber quedado libre, este

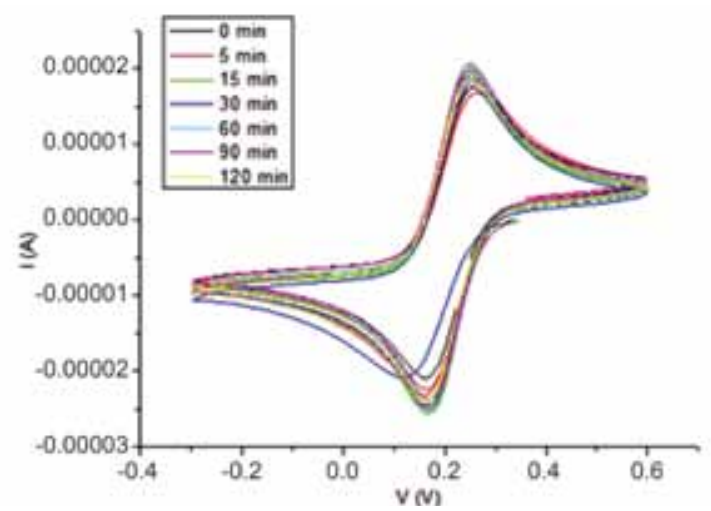

impedimento será el responsable en la disminución de las corrientes absolutas de pico que se aprecia en los voltamperogramas.

La disminución en la capacidad del electrodo para reducir u oxidar una sustancia es más notorio cuando este ha sido funcionalizado, ya que el grupo orgánico que ingresa en dicha funcionalización es mucho más voluminoso y ejercerá un efecto impedimétrico y de repulsión mucho más evidente que cuando el electrodo ha sido tratado con CA.

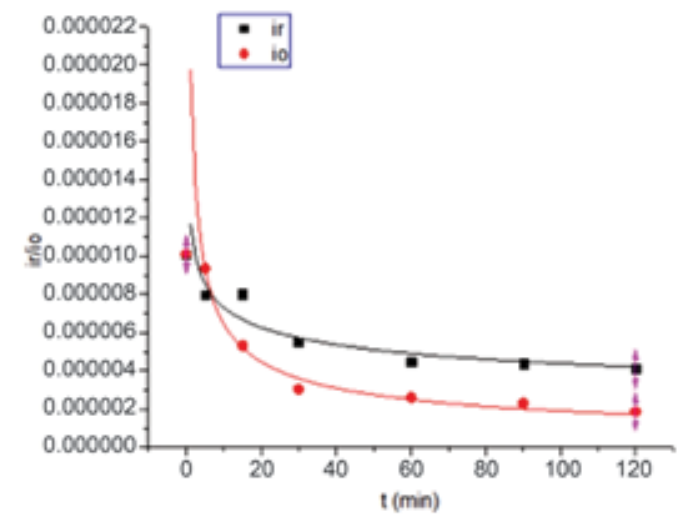

Figura 4. Izquierda: Voltamperogramas realizados cuando el electrodo es mantenido en solución de $M P C$ a $40^{\circ} \mathrm{C}$. Derecha: Valores de corrientes de pico de oxidación $\left(i_{o}\right)$ y reducción $\left(i_{r}\right)$ obtenidos de los voltamperogramas del lado izquierdo. 
El hecho de que al hacer reaccionar la capa de CA con MPC a $40{ }^{\circ} \mathrm{C}$, la electrólisis de hexacianoferrato(III/II) se vuelva más lenta puede demostrarse mediante EIS, como puede verse en la Figura 5. Esto puede deberse a la mayor distancia que se establece entre la superficie del electrodo y las moléculas electroactivas; si bien aún falta llevar a cabo más estudios para establecer la razón verdadera de este comportamiento. En la Figura 5 puede observarse claramente que, a frecuencias bajas, la respuesta electroquímica del par del mediador deja de estar controlada por difusión para mantenerse bajo un control cinético, pues la contribución tipo Warburg que se ve en la curva a de la Figura 5 desaparece al modificar el electrodo cubierto con CA con el MPC.

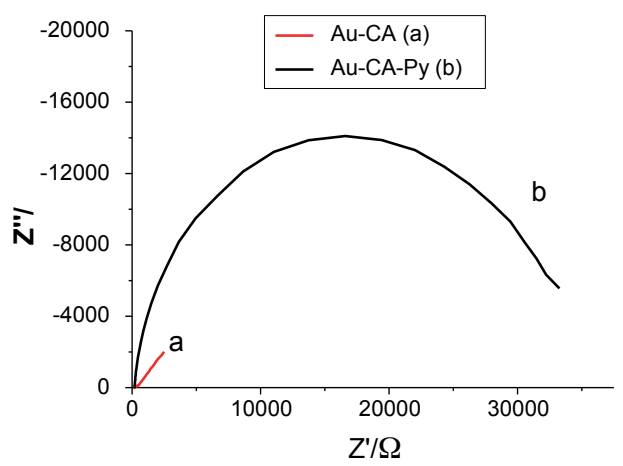

Figura 5. Diagramas de Nyquist para demostrar la funcionalización con MPC. (a) Modificación de electrodo de oro con $C A$ y (b) Funcionalización de dicho electrodo con MPC (Py) durante 60 minutos. Dichos experimentos se llevaron a cabo a un potencial de media onda (0.21V) en ferricianuro.

3.3. Evolución de la respuesta electroquímica de los electrodos modificados en función del tiempo de residencia en una disolución amortiguadora

Como se mencionó anteriormente, es necesario evaluar el comportamiento de los electrodos comparando su comportamiento frente a las soluciones de cobre y también cuando estos son mantenidos en la solución de fosfatos. Esta parte del trabajo se llevó a cabo para determinar si la monocapa formada sobre el electrodo de oro modificaba su comportamiento respecto del mediador, cuando se le permite evolucionar libremente, manteniéndola inmersa en un medio controlado. En

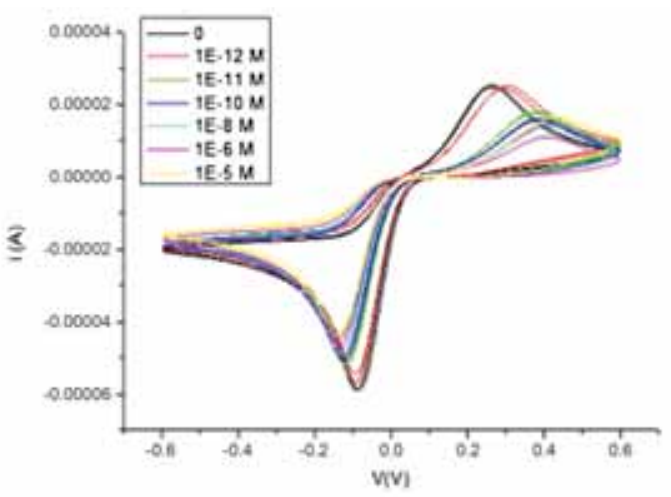

las ilustraciones siguientes se muestran los resultados de este estudio, que se obtuvieron de mediciones de VC y EIS, los cuales implican que la interfase electrodo modificado-disolución se estabiliza muy lentamente, posiblemente por una alteración de la conformación de la monocapa, lo cual dificulta que estos electrodos puedan utilizarse como sensores.

Para dichos experimentos se utilizó como mediador PBQ debido a que el ferricianuro tiende a formar complejos con el cobre. El barrido en este caso se realizó desde un valor de $-0.6 \mathrm{~V}$ a $0.6 \mathrm{~V}$ y el potencial de media onda al que se realizaron los barridos de EIS fue de $0.09 \mathrm{~V}$.

Figura 6. Izquierda: Voltamperogramas realizados cuando el electrodo de oro es mantenido en soluciones de cobre de varias concentraciones 30 minutos en cada una. Derecha: Voltamperogramas cuando el electrodo de oro es mantenido en solución de fosfatos en tiempos equivalentes a los que pasa en las soluciones de cobre. 

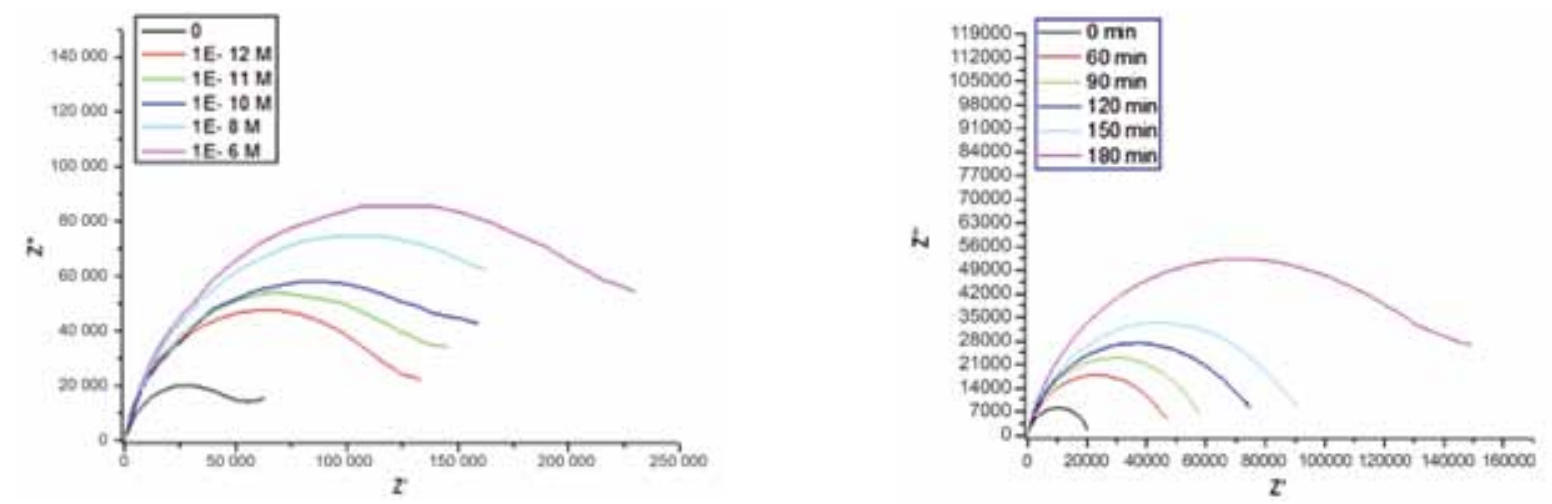

Figura 6. Izquierda: Voltamperogramas realizados cuando el electrodo de oro es mantenido en soluciones de cobre de varias concentraciones 30 minutos en cada una. Derecha: Voltamperogramas cuando el electrodo de oro es mantenido en solución de fosfatos en tiempos equivalentes a los que pasa en las soluciones de cobre.

Como puede apreciarse en las figuras, el electrodo cambia su comportamiento cuando está inmerso en la solución de cobre; pero, también cambia su respuesta cuando está expuesto a la solución de fosfatos, por lo que nos es posible tener una medición solo de la interacción con el metal, lo que dificulta la cuantificación del mismo.

\section{Conclusiones}

- Se estudiaron las propiedades electroquímicas de superficies de oro modificadas con cisteamina y funcionalizadas con 6-metil-2-piridincarboxaldehido, encontrándose que las capas adsorbidas sobre los electrodos de oro se estabilizan muy lentamente en la solución buffer, por lo que no es posible la utilización de este tipo de electrodos de oro modificados como un sensor para cobre o mercurio.

- La formación de la monocapa autoensamblada de cisteamina fue estudiada utilizando técnicas de Voltamperometría Cíclica y Espectroscopia Electroquímica de Impedancia, y en base a dicho estudio pudo determinarse que el tiempo mínimo requerido para la formación de la monocapa de cisteamina sobre los electrodos de oro era de $80 \mathrm{~min}$, y para asegurarnos que la monocapa se ordene espacialmente, se procedió a dejar los electrodos inmersos en CA por 3 horas.

- Es posible estudiar la funcionalización de la monocapa con 6-metil-2-piridincarboxaldehido, utilizando técnicas de Voltamperometría Cíclica y Espectroscopia Electroquímica de Impedancia y en base a dicho estudio pudo determinarse que el tiempo mínimo requerido para que la funcionalización concluya de forma óptima es de $60 \mathrm{~min}$, y para asegurarnos una reacción total se mantuvo los electrodos en solución de MPC durante 2 horas.

- Cuando el sensor se somete a la acción de soluciones de cobre y mercurio de varias concentraciones es posible apreciar cambios eléctricos tanto en los voltamperogramas cuanto en los diagramas de Nyquist; pero, no es posible compensar dichos cambios frente a las respuestas que provoca la solución buffer en la que se preparan las soluciones de los metales.

\section{Referencias}

1. Reza, Karimi, Seyed, Ahmad, "Cooper (II) Nanosensor Base on a Gold Cysteamine Self-Assembled Monolayer Functionalized with Salicylaldehyde" Anal. Chem, 2006, 4957-4963.

2. Love, Christopher; Estroff, Lara; Kriebel, Jennah; Nuzzo, Ralph; Whitesides, George "Self-Assembled Monolayers of Thiolates on Metals as a Form of Nanotechnology", Chem. Rev. 2005.

3. Godínez, Luis "Substratos modificados con monocapas autoensambladas: dispositivos para fabricar sensores y estudiar procesos químicos y fisicoquímicos interfaciales" Revista de la Sociedad Química de México, Vol. 43, Núm. 6 (1999). 